\title{
Changes of Volatile Flavor Compounds in Large Yellow Croaker (Larimichthys crocea) during Storage, as Evaluated by Headspace Gas Chromatography-Ion Mobility Spectrometry and Principal Component Analysis
}

\author{
Tengfei Zhao $^{1}{ }^{\mathbb{D}}$, Soottawat Benjakul ${ }^{2} \mathbb{D}$, Chiara Sanmartin ${ }^{3} \mathbb{D}$, Xiaoguo Ying ${ }^{1,4, *}$, Lukai Ma ${ }^{5,6, *}$, \\ Gengsheng Xiao ${ }^{5}$, Jin Yu ${ }^{7}$, Guoqin Liu ${ }^{8}$ and Shanggui Deng ${ }^{1}$
}

1 Zhejiang Provincial Key Laboratory of Health Risk Factors for Seafood, Collaborative Innovation Center of Seafood Deep Processing, College of Food and Pharmacy, Zhejiang Ocean University, Zhoushan 316022, China; Zhaotengfei1996@yeah.net (T.Z.); dengshanggui@163.com (S.D.)

2 International Center of Excellence in Seafood Science and Innovation, Faculty of Agro-Industry, Prince of Songkla University, Hat Yai, Songkhla 90110, Thailand; soottawat.b@psu.ac.th

3 Department of Agriculture, Food and Environment (DAFE), Pisa University, Via del Borghetto, 80, 56124 Pisa, Italy; chiara.sanmartin@unipi.it

4 College of Biosystems Engineering and Food Science, Zhejiang University, Hangzhou 310058, China

check for updates

Citation: Zhao, T.; Benjakul, S. Sanmartin, C.; Ying, X.; Ma, L.; Xiao, G.; Yu, J.; Liu, G.; Deng, S. Changes of Volatile Flavor Compounds in Large Yellow Croaker (Larimichthys crocea) during Storage, as Evaluated by Headspace Gas Chromatography-Ion Mobility Spectrometry and Principal Component Analysis. Foods 2021, 10, 2917. https://doi.org/10.3390/ foods10122917

Academic Editors: Federico Marini and Alessandra Biancolillo

Received: 22 October 2021

Accepted: 22 November 2021

Published: 25 November 2021

Publisher's Note: MDPI stays neutral with regard to jurisdictional claims in published maps and institutional affiliations.

Copyright: (c) 2021 by the authors. Licensee MDPI, Basel, Switzerland. This article is an open access article distributed under the terms and conditions of the Creative Commons Attribution (CC BY) license (https:// creativecommons.org/licenses/by/ $4.0 /)$.
5 Guangdong Provincial Key Laboratory of Lingnan Specialty Food Science and Technology, College of Light Industry and Food, Zhongkai University of Agriculture and Engineering, Guangzhou 510225, China; Gshxiao@aliyun.com

6 Academy of Contemporary Agricultural Engineering Innovations, Zhongkai University of Agriculture and Engineering, Guangzhou 510225, China

7 Longyou Aquaculture Development Center, Agricultural and Rural Bureau of Longyou County, Quzhou 324000, China; Z18858398133@163.com

8 School of Food Science and Engineering, South China University of Technology, Guangzhou 510640, China; guoqin@scut.edu.cn

* Correspondence: yingxiaoguo@zjou.edu.cn (X.Y.); malukai@zhku.edu.cn (L.M.)

Abstract: The large yellow croaker is one of the most economically important fish in Zhoushan, Zhejiang Province, and is well known for its high protein and fat contents, fresh and tender meat, and soft taste. However, the mechanisms involved in its flavor changes during storage have yet to be revealed, although lipid oxidation has been considered to be one important process in determining such changes. Thus, to explore the changes in the flavor of large yellow croaker fish meat during different storage periods, the main physical and chemical characteristics of the fish meat, including the acid value, peroxide value, $p$-anisidine value, conjugated diene value, and identities of the various flavor substances, were investigated and analyzed by multivariable methods, including headspace gas chromatography-ion mobility spectrometry (GC-IMS) and principal component analysis (PCA). It was found that after $60 \mathrm{~d}$ storage, the types and contents of the aldehyde and ketone aroma components increased significantly, while after $120 \mathrm{~d}$, the contents of ketones (2-butanone), alcohols (1-propanethiol), and aldehydes (n-nonanal) decreased significantly. More specifically, aldehyde components dominated over ketones and lipids, while the $n$-nonanal content showed a downward trend during storage, and the 3-methylbutanol (trimer), 3-methylbutanol (dimer, D), 3-pentanone (D), and 3-pentanone (monomer) contents increased, whereas these compounds were identified as the key components affecting the fish meat flavor. Furthermore, after $120 \mathrm{~d}$ storage, the number of different flavor components reached its highest value, thereby confirming that the storage time influences the flavor of large yellow croaker fish. In this context, it should be noted that many of these compounds form through the Maillard reaction to accelerate the deterioration of fish meat. It was also found that after storage for $120 \mathrm{~d}$, the physical indices of large yellow croaker meat showed significant changes, and its physicochemical properties varied. These results therefore demonstrate that a combination of GC-IMS and PCA can be used to identify the differences in flavor components present in fish meat during storage. Our study provides useful knowledge for understanding the different flavors associated with fish meat products during and following storage. 
Keywords: large yellow croaker (Larimichthys crocea); electronic nose; gas chromatography-ion mobility spectrometry; peroxidation value; volatile organic compounds

\section{Introduction}

The large yellow croaker (Larimichthys crocea) is a prized commercial fish in China and is considered one of the traditional "four major marine products." This fish is distributed over three geographical locations in China, namely in the East China Sea (the northern part of the Yellow Sea including Lu Yanyu, Yushuyang, Lushan fishery, and other waters), the Guangdong group (mainly in the Taiwan Strait), and the western group (the South China Sea between the Qiongzhou Straight and the mouth of the Pearl River). The meat of the large yellow croaker is nutritious and contains a variety of unsaturated fatty acids and amino acids, its texture is delicate and crisp, and its taste is delicious [1-3]. As a result, this fish is a popular seafood among consumers.

In terms of the analyses of flavor compounds in such foods, current analytical techniques, such as gas chromatography (GC) and GC-mass spectrometry (MS), require solidphase microextraction (SPME) and/or post-treatments [4,5]. By contrast, headspace-gas chromatography-ion mobility spectrometry (HS-GC-IMS) requires no pretreatment, as the solid, liquid, or headspace gas samples are injected directly [6,7]. This method also displays a particularly high sensitivity (at the ppb level) [8,9] and fast detection [10]. Therefore, GC-IMS is promising for identifying product varieties, carrying out quality control, monitoring product freshness, and estimating product shelf lives [11-13]. Previously, HSGC-IMS and HS-SPME-GC-MS have been used to reveal the fingerprints and changes in the aroma of soybeans during fermentation, wherein 115 volatile organic compounds were successfully identified. In addition, through the fingerprint analysis of olive oil by GC-IMS, 39 volatile organic compounds were found to change significantly during fermentation, thereby confirming that IMS can identify different food flavor components [14]. It has also been suggested that GC-IMS could be employed to examine the changes in lipid flavor compounds during the processing of meat, and it was found that the volatile organic compounds (alcohols, aldehydes, ketones, heterocyclic compounds, aromatic hydrocarbons, and esters) present in different meat products can be identified through fingerprinting by such techniques [15-17]. However, few reports have been published on the organic volatile fingerprints of large yellow croaker meat after different storage periods [18].

Thus, we herein report the use of GC-IMS to identify changes in the volatile flavor substances of large yellow croaker meat during its oxidation under storage. By measuring the acid value, the peroxide value, the $p$-anisidine value, and the conjugated diene value of the fish meat, its oxidative deterioration is evaluated, and the fingerprint of volatile flavor compounds is established. Ultimately, we aim to provide information to permit exploration of the changes in volatile flavor substances in large yellow croaker meat during storage for different periods of time and to provide theoretical support for its quality control during storage.

\section{Materials and Methods}

\subsection{Fish Samples}

The large yellow croaker samples used in this experiment were provided by the Ocean Family Fishery (Zhoushan Xincheng, Zhejiang, China) and were transported to the Seafood Health Risk Factors Laboratory at Zhejiang Ocean University later. The fish samples had a body length of $19.40-24.00 \mathrm{~cm}$ and a weight range of $270.50-320.70 \mathrm{~g}$. All samples were stored at $-18{ }^{\circ} \mathrm{C}$ for $2 \mathrm{~d}$ after capture (the minimum time required to reach land). The yellow croaker fish selected for the purpose of this study originated from Zhoushan (Zhejiang), in the Zhoushan Islands. The dorsal and upper sides of the fish are yellowish brown, the lower and ventral sides are golden yellow, and the head is large. This fish is rich in proteins, trace elements, and vitamins, which are important in the context of 
human nutrition. In addition, the salt-soluble protein content can reach $11.90 \mathrm{~g} / 100 \mathrm{~g}$, the water-soluble protein content can reach $14.27 \mathrm{~g} / 100 \mathrm{~g}$, the water content can reach $61.85 \mathrm{~g} / 100 \mathrm{~g}$, and the ash content can reach $0.80 \mathrm{~g} / 100 \mathrm{~g}$.

\subsection{Reagents and Chemicals}

The following chemicals were purchased from Sinopharm Chemical Reagent Co., Ltd. (Shanghai, China): ethanol, petroleum ether, sodium thiosulfate, anhydrous sodium carbonate, acetic acid, isooctane, $n$-hexane, trichloromethane, sodium sulfate, $n$-heptane, potassium iodide, phenol, phenolphthalein, potassium hydroxide, tetrahydrofuran, and alumina. All other reagents were of analytical grade and were commercially available.

\subsection{Sample Processing}

The fish samples were stored in a freezer at $-18{ }^{\circ} \mathrm{C}$ (MDF-U53V, Sanyo, Japan) and at a relative humidity of $60-75 \%$ for $0,5,10,20,30,40,60,90$, and $120 \mathrm{~d}$. At the desired time, the fish meat was cut and homogenized at 10,000 rpm for $20 \mathrm{~s}$ (FJ200-S, Hunan Li Chen Instrument Technology Company, Changsha, China) to produce a slurry, as outlined in Figure 1. To identify the volatile components present in the large yellow croaker fish samples after different storage periods, GC-IMS (see Section 2.6.2) was used to analyze the samples after $0,60,90$, and $120 \mathrm{~d}$.
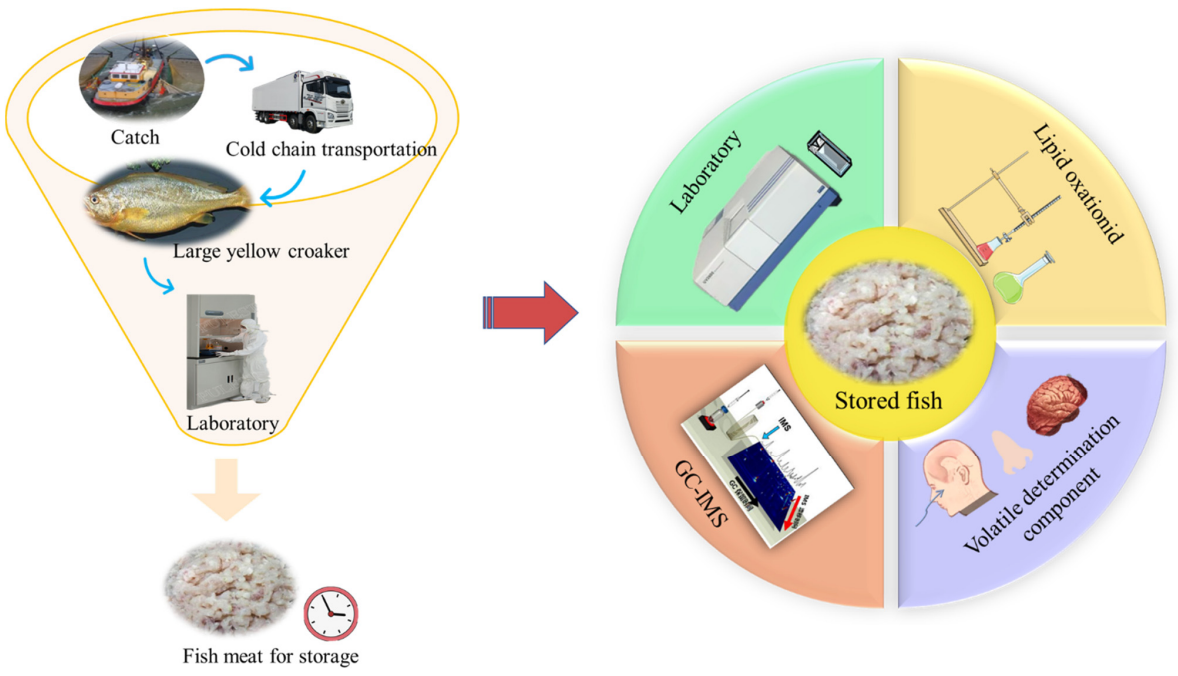

Figure 1. Schematic diagram of the methods employed for analysis of large yellow croaker fish meat.

\subsection{Determination of the Lipid Profiles}

The official methods of the American Oil Chemists Society (AOCS) were used to determine the acid values (AV) (Ca 5a-40), the peroxide values (POV) (Cd 8b-90), and the $p$-anisidine values $(p-\mathrm{AV})(\mathrm{Cd} 18-90)$ of the various samples. Determination of the conjugated diene value (CDV) was carried out using a modification of the technique, as described below [19].

\subsubsection{Acid Values}

The AV can be used as an indicator of the degree of oil deterioration. To prepare the phenolphthalein indicator required for this measurement, phenolphthalein (1.00 g) was accurately weighed (AR224-CN, Electronic Balance, Orhaus Instruments (Shanghai) Co., Ltd., Shanghai, China) and completely dissolved in $95 \%$ ethanol with ultrasonication. After transferring to a $100 \mathrm{~mL}$ volumetric flask, the volume was made up to capacity with $95 \%$ ethanol. A standard solution of $0.01 \mathrm{~mol} / \mathrm{L}$ potassium hydroxide was prepared by dissolving potassium hydroxide $(0.56 \mathrm{~g})$ in deionized water $(1000 \mathrm{~mL})$. Fish meat samples $(5.00 \mathrm{~g})$ subjected to different storage periods were homogenized $(5000 \mathrm{rpm})$ and placed in a $100 \mathrm{~mL}$ conical flask. The hydrolysate was prepared by adding a mixture of petroleum ether 
and ethanol $(2: 1 v / v, 50 \mathrm{~mL})$ and 2-3 drops of the phenolphthalein indicator. Subsequently, the mixture was titrated with a $0.01 \mathrm{~mol} / \mathrm{L}$ potassium hydroxide standard solution. The $\mathrm{AV}(\mathrm{mg} / \mathrm{g}$ ) was calculated according to Equation (1):

$$
\mathrm{AV}=(\mathrm{v} \times \mathrm{c} \times 56.1) / \mathrm{m}
$$

where $\mathrm{v}$ is the volume of potassium hydroxide solution $(\mathrm{mL}), \mathrm{c}$ is the concentration of potassium hydroxide (mol/L), $\mathrm{m}$ is the quality of the meat sample (g), and 56.1 is the molar mass $(\mathrm{g} / \mathrm{mol})$ of potassium hydroxide.

\subsubsection{Peroxide Values}

The fish meat sample was wiped with absorbent paper to remove water and watersoluble impurities. The fish meat sample $(5.00 \mathrm{~g})$ was then added to a $250 \mathrm{~mL}$ Erlenmeyer flask and a 3:2 $(v / v)$ acetic acid-isooctane solution $(5 \mathrm{~mL})$ was added and swirled to mix well. Subsequently, a saturated potassium iodide $(\mathrm{KI})$ solution $(0.5 \mathrm{~mL})$ was added to the sample and allowed to stand for exactly $1 \mathrm{~min}$. After this time, distilled water $(30 \mathrm{~mL})$ was added, and the mixture was swirled to mix well. The sample was then titrated with a $0.005 \mathrm{~N}$ sodium thiosulfate solution until light yellow color appeared. Subsequently, the starch indicator solution $(0.50 \mathrm{~mL},>95 \%$ purity) was titrated under agitation until the solution turned colorless. A blank sample was also prepared without the addition of the fish meat sample. The POV (meq/kg) was calculated according to Equation (2):

$$
\mathrm{POV}=(1000 \times \mathrm{v} \times \mathrm{c}) / \mathrm{m}
$$

where $\mathrm{v}$ is the volume of sodium thiosulfate solution $(\mathrm{mL}), \mathrm{c}$ is the concentration of the sodium thiosulfate standard solution, and $\mathrm{m}$ is the mass of fish meat $(\mathrm{g})$.

\subsection{3. $p$-Anisidine Values}

The fish meat sample was wiped with absorbent paper, and the $p$-anisidine solution was prepared by adding $p$-anisidine $(0.125 \mathrm{~g})$ to glacial acetic acid $(50 \mathrm{~mL})$. A sample $(2.00 \mathrm{~g})$ of the fish meat was then added to a $25 \mathrm{~mL}$ volumetric flask, and isooctane $(25 \mathrm{~mL})$ was added prior to swirling to mix well. The absorbance $\left(\mathrm{A}_{0}\right)$ of the resulting solution was measured at $350 \mathrm{~nm}$ using a spectrophotometer (UV-2600, Tianjin, China). An aliquot $(5 \mathrm{~mL})$ of the solution sample was then pipetted into a test tube, and the $\mathrm{p}$-anisidine reagent $(1 \mathrm{~mL})$ was added. After $10 \mathrm{~min}$, the sample absorbance (A1) was measured at $350 \mathrm{~nm}$. For the blank sample, isooctane $(5 \mathrm{~mL})$ and the $p$-anisidine reagent $(1 \mathrm{~mL})$ were added to a separate test tube. The dimensionless $p$-AV was calculated according to Equation (3):

$$
p-\mathrm{AV}=25\left(1.2 \mathrm{~A}_{1}-\mathrm{A}_{0}\right) / \mathrm{W}
$$

where $\mathrm{W}$ is the weight of the fish meat $(\mathrm{g}), \mathrm{A}_{1}$ is the absorbance of the fat solution after reaction with the $p$-anisidine reagent, $\mathrm{A}_{0}$ is the absorbance of the fat solution, 25 is the sample volume $(25 \mathrm{~mL})$, and 1.2 is the correction factor.

\subsubsection{Conjugated Diene Values}

The fish meat sample was weighed and placed in a small beaker. After the addition of isooctane $(5 \mathrm{~mL})$ to dissolve the sample, the volume was adjusted to $50 \mathrm{~mL}$ using an additional volume of isooctane. The optical absorption of the obtained solution was then measured at $232 \mathrm{~nm}$ (UV-2600, Yerco Instrument Co., Ltd., Shenzhen, China) using isooctane as the zero reference. The CDV was calculated according to Equation (4):

$$
\mathrm{CDV}=\mathrm{AqC} \times 1
$$

where Aq is the absorbance of the sample at $232 \mathrm{~nm}, \mathrm{C}$ is the concentration of the sample $(\mathrm{g} / 100 \mathrm{~mL})$ (the solute is the fish meat and the solvent is isooctane), and $1(\mathrm{~cm})$ is the length of the quartz cell. 


\subsection{Aroma Detection at Different Points during Storage}

For sample pretreatment, the fish meat $(10.00 \mathrm{~g})$ was sealed in a capped bottle and allowed to stand for $30 \mathrm{~min}$ to allow the volatile compounds to equilibrate in the air. An electronic nose (PEN3, Airsense, Berlin, Germany) was employed under previously reported conditions $(n=3)$ [20]. The detection time was $200 \mathrm{~s}$, the sensor cleaning time was 300-500 s, and the data acquisition time was 199-200 s. The various sensors are described in Table S1.

\subsection{Volatile Compound Analysis at Different Points during Storage 2.6.1. Sample Processing}

After thawing at $4{ }^{\circ} \mathrm{C}$ in a refrigerator, the fish meat sample $(5.00 \mathrm{~g})$ was placed in a $20 \mathrm{~mL}$ headspace bottle equipped with a magnetic screw seal and incubated $40{ }^{\circ} \mathrm{C}$ for $20 \mathrm{~min}$. GC-IMS analysis was then carried out in triplicate for each sample.

\subsubsection{Headspace Gas Chromatography-Ion Mobility Spectrometry (GC-IMS)}

These analyses were performed on a FlavourSpec ${ }^{\circledR}$ GC-IMS system (G.A.S Company, Berlin, Germany) equipped with a 490 micro gas chromatograph (Agilent, Palo Alto, CA, USA), an autosampler (Solid-Phase Microextraction, 57330-U, Supelco, PA, USA), and a headspace sampling unit (Supelco, PA, USA). The GC was equipped with an FS-SE-54-CB-1 capillary column $(15 \mathrm{~m} \times 0.53 \mathrm{~mm})$ (Nicolet, PA, USA). The samples in the headspace vials were incubated at $70{ }^{\circ} \mathrm{C}$ for $20 \mathrm{~min}$, and after this time, a sample $(500 \mu \mathrm{L})$ of the headspace was injected automatically $\left(80^{\circ} \mathrm{C}\right.$, splitless mode) via a heated syringe at $50{ }^{\circ} \mathrm{C}$. The flow of the carrier gas was programmed as follows: $2 \mathrm{~mL} / \mathrm{min}$ for $0-2 \mathrm{~min}, 30 \mathrm{~mL} / \mathrm{min}$ for $1-10 \mathrm{~min}, 100 \mathrm{~mL} / \mathrm{min}$ for $10-20 \mathrm{~min}$, and $130 \mathrm{~mL} / \mathrm{min}$ for $20-45 \mathrm{~min}$. The analytes were eluted and separated at $40{ }^{\circ} \mathrm{C}$, then ionized in the IMS ionization chamber by a $3 \mathrm{H}$ ionization source (300 MBq activity) in the positive ion mode. The $9.8 \mathrm{~cm}$ drift tube was operated at a constant voltage $(5 \mathrm{kV})$ at $45^{\circ} \mathrm{C}$ with a nitrogen flow of $150 \mathrm{~mL} / \mathrm{min}$. Each spectrum was reported as an average of 12 scans. The syringe was automatically flushed with a stream of nitrogen for $30 \mathrm{~s}$ before each analysis and $5 \mathrm{~min}$ after each analysis to avoid cross contamination. The retention index (RI) of each compound was calculated using $n$-ketones $\mathrm{C}_{4}-\mathrm{C}_{9}$ (Sinopharm Chemical Reagent Beijing Co., Ltd., Beijing, China) as external references and the calculations were performed by the automated mass spectral deconvolution and identification system. The identification of volatile compounds was performed by comparing the RIs and drift times, and the content of volatile compounds was quantified based on the HS-GC-IMS peak intensity.

\subsection{Data Processing}

All measurements were carried out three times in parallel, and Origin software (OriginLab Corporation, Northampton, MA, USA) was used for data analysis. The values are reported as "mean \pm standard deviation" and were analyzed using SPSS 24.0 software (Chicago, IL, USA). The multi-comparison was obtained at $p<0.05$. The structures of the volatile compounds were identified based on the built-in IMS database. PCA was carried out using the dynamic PCA plug-in program.

\section{Results and Analysis}

\subsection{Effect of the Storage Time on Lipid Oxidation in Large Yellow Croaker}

Four indicators (i.e., the $\mathrm{AV}, \mathrm{POV}, p-\mathrm{AV}$, and $\mathrm{CDV}$ ) were used to assess the degree of oxidation in the meat of large yellow croaker during storage. As shown in Figure 2, all four values increased significantly during storage $(p<0.05)$. In the fresh fish $(0 \mathrm{~d})$, the AV, POV, $p-\mathrm{AV}$, and CDV were $2.02 \pm 0.12 \mathrm{mg} / \mathrm{g}, 4.51 \pm 0.51 \mathrm{meq} / \mathrm{kg}, 0.40 \pm 0.04$, and $12.43 \pm 0.56$, respectively, thereby indicating that the fresh fish meat contains a rich variety of lipid products [21]. After $90 \mathrm{~d}$, these values increased to $5.02 \pm 0.11 \mathrm{mg} / \mathrm{g}$, $18.55 \pm 0.64 \mathrm{meq} / \mathrm{kg}, 1.47 \pm 0.04$, and $24.59 \pm 0.78$, respectively. In particular, the POV increased almost fourfold during this storage period, likely due to hydrogen peroxide being 
the main product of fish lipid oxidation [22,23]. As the storage period was lengthened, fat oxidation in the fish meat led to a further increase in the POV. More specifically, after $120 \mathrm{~d}$, the $\mathrm{AV}$, POV, p-AV, and CDV were $7.62 \pm 0.14 \mathrm{mg} / \mathrm{g}, 23.67 \pm 0.55 \mathrm{meq} / \mathrm{kg}, 2.33 \pm 0.03$, and $33.57 \pm 0.89$, respectively. This observed increase in the $\mathrm{AV}$ is also consistent with previous studies $[24,25]$ and is closely related to the free fatty acid content $[26,27]$. Previously, it was reported that the oxidation of fish meat during storage causes the breakage of ester bonds, which releases a large amount of free fatty acids and increases the AV [28]. In terms of the $p-\mathrm{AV}$, this value represents the content of secondary products in the fish meat, including aldehydes, ketone alcohols, and acids [29]. It was found that after $120 \mathrm{~d}$, the $p$-AV approached the POV, thereby confirming an increased content of oxidation products in the fish sample [30]. In this context, it has been reported that $p-\mathrm{AV}$ increases with time due to the decomposition of secondary oxidation products [31]. As outlined in Table 1, the hexanal (M), hexanal (D), and benzaldehyde contents increased significantly from $453.89,237.69$, and $232.42 \mathrm{mg}$ at day 0 to $765.02,316.81$, and $400.98 \mathrm{mg}$, respectively, after $120 \mathrm{~d}$. Similarly, the contents of ketones 3-octanone, 2-heptanone (M), and 2-heptanone (D) increased from 197.55, 226, and 33.98, at day 0 to $549.19,770.82$, and 129.45 , respectively, after $120 \mathrm{~d}$. These observations suggest that after storage for $120 \mathrm{~d}$, the fish meat had undergone a significant degree of spoiling, which would likely have a detrimental effect on its flavor. It should be noted here that the letters $\mathrm{M}, \mathrm{D}$, and $\mathrm{T}$ in parentheses after a substance name represent the monomer, dimer, and trimer of the substance, respectively.
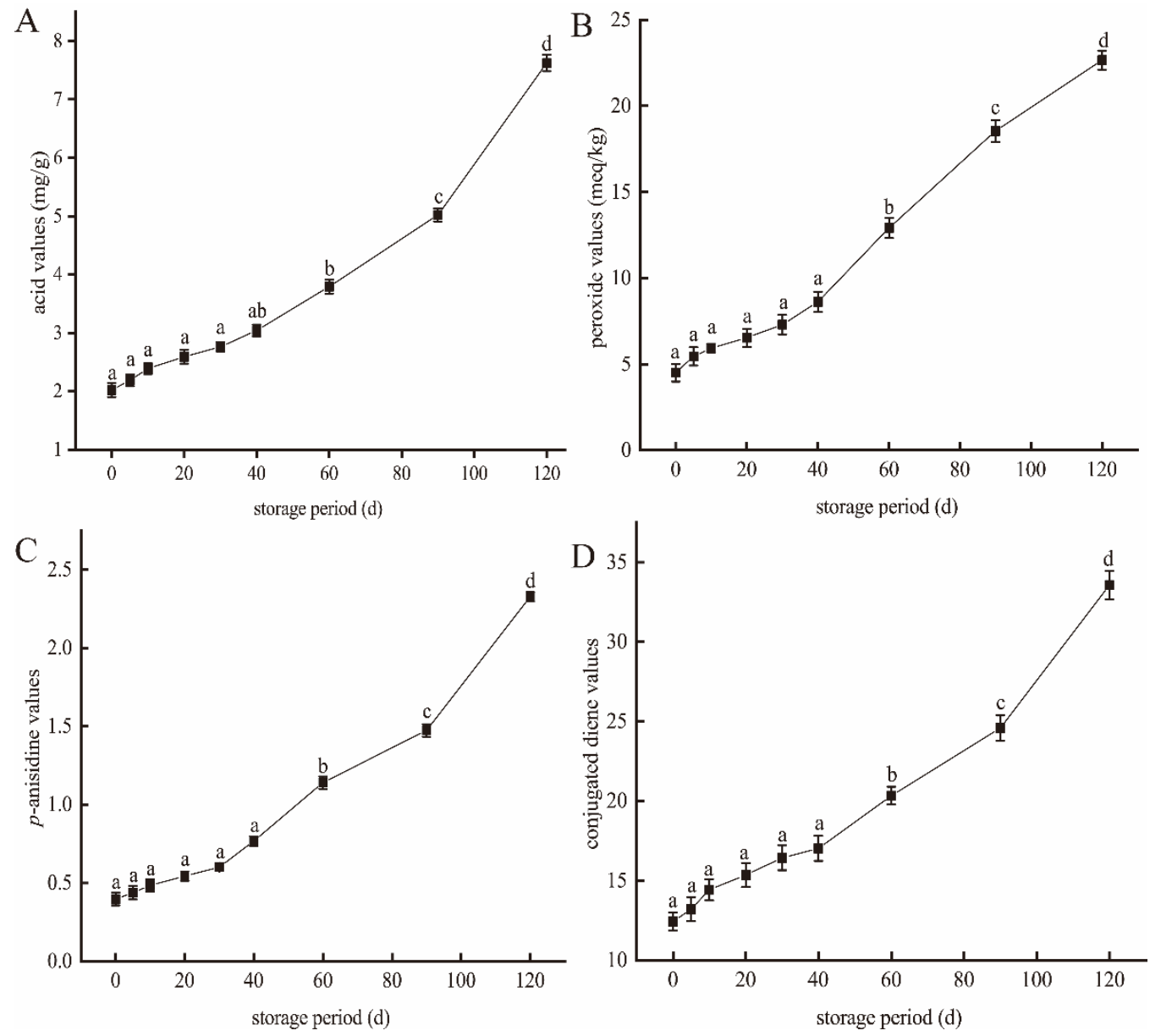

Figure 2. Evaluation of the lipid oxidation taking place in the meat of large yellow croaker fish after different storage periods. Note: (A) Acid values, (B) peroxide values, (C) p-anisidine values, and (D) conjugated diene values. The $\mathrm{p}$-anisidine and conjugated diene values are dimensionless. Letters a-d indicate significant differences. The data are presented as means $\pm \operatorname{SD}(n=3)$. 
Table 1. Qualitative analysis of the flavor compounds present in large yellow croaker meat after different storage periods.

\begin{tabular}{|c|c|c|c|c|c|c|c|c|c|c|c|}
\hline \multirow{2}{*}{ No. } & \multirow{2}{*}{ Compound } & \multirow{2}{*}{ CAS\# } & \multirow{2}{*}{$\begin{array}{l}\text { Molecule } \\
\text { Formula }\end{array}$} & \multirow{2}{*}{ MW } & \multirow{2}{*}{ RI1 } & \multirow{2}{*}{ RT2 } & \multirow{2}{*}{ DT3 } & \multicolumn{4}{|c|}{ Storage Period } \\
\hline & & & & & & & & $0 \mathrm{~d}$ & $60 \mathrm{~d}$ & $90 \mathrm{~d}$ & $120 \mathrm{~d}$ \\
\hline 1 & 3-Octanone & C106683 & $\mathrm{C}_{8} \mathrm{H}_{16} \mathrm{O}$ & 128.2 & 992.4 & 540.9 & 1.31 & 197.55 & 232.44 & 439.69 & 549.19 \\
\hline 2 & 2-Heptanone (M) & C110430 & $\mathrm{C}_{7} \mathrm{H}_{14} \mathrm{O}$ & 114.2 & 892 & 367.6 & 1.256 & 226 & 367.96 & 572.06 & 770.82 \\
\hline 3 & 2-Heptanone (D) & C110430 & $\mathrm{C}_{7} \mathrm{H}_{14} \mathrm{O}$ & 114.2 & 889.2 & 364 & 1.625 & 33.98 & 46.23 & 99.86 & 129.45 \\
\hline 4 & 3-Hydroxy-2-butanone (M) & C513860 & $\mathrm{C}_{4} \mathrm{H}_{8} \mathrm{O}_{2}$ & 88.1 & 716.1 & 192.3 & 1.068 & 1336.8 & 1350.1 & 1362.8 & 1376.56 \\
\hline 5 & 3-Hydroxy-2-butanone (D) & C513860 & $\mathrm{C}_{4} \mathrm{H}_{8} \mathrm{O}_{2}$ & 88.1 & 715.8 & 192 & 1.326 & 884.81 & 914.77 & 953.59 & 987.56 \\
\hline 6 & 3-Pentanone (M) & C96220 & $\mathrm{C}_{5} \mathrm{H}_{10} \mathrm{O}$ & 86.1 & 696.6 & 178.5 & 1.108 & 260.51 & 339.22 & 389.51 & 518.62 \\
\hline 7 & 3-Pentanone (D) & C96220 & $\mathrm{C}_{5} \mathrm{H}_{10} \mathrm{O}$ & 86.1 & 694.1 & 176.8 & 1.351 & 1270.9 & 1472 & 1588.4 & 1631.99 \\
\hline 8 & 2-Butanone & C78933 & $\mathrm{C}_{4} \mathrm{H}_{8} \mathrm{O}$ & 72.1 & 590.9 & 129.7 & 1.057 & 624.73 & 561.24 & 483.93 & 321.34 \\
\hline 9 & 1-Hexanol & C111273 & $\mathrm{C}_{6} \mathrm{H}_{14} \mathrm{O}$ & 102.2 & 879.8 & 351.9 & 1.326 & 225.16 & 122.06 & 83.02 & 94.84 \\
\hline 10 & 3-Methylbutanol (D) & C123513 & $\mathrm{C}_{5} \mathrm{H}_{12} \mathrm{O}$ & 88.1 & 739.9 & 210.7 & 1.499 & 202.46 & 505.84 & 820 & 1088.71 \\
\hline 11 & 1-Penten-3-ol & C616251 & $\mathrm{C}_{5} \mathrm{H}_{10} \mathrm{O}$ & 86.1 & 690.1 & 174.1 & 0.944 & 226.6 & 248.48 & 305.92 & 339.2 \\
\hline 12 & 1-Propanethiol & C107039 & $\mathrm{C}_{3} \mathrm{H}_{8} \mathrm{~S}$ & 76.2 & 633.3 & 147 & 1.36 & 109.48 & 82.32 & 50.17 & 47.2 \\
\hline 13 & 3-Methylbutanol (T) & C123513 & $\mathrm{C}_{5} \mathrm{H}_{12} \mathrm{O}$ & 88.1 & 738.8 & 209.8 & 1.788 & 56.03 & 67.77 & 97.83 & 126.9 \\
\hline 14 & Ethanol & C64175 & $\mathrm{C}_{2} \mathrm{H}_{6} \mathrm{O}$ & 46.1 & 491.5 & 96.79 & 1.046 & 975.52 & 911.11 & 711.76 & 518.53 \\
\hline 15 & Hexanal (M) & C66251 & $\mathrm{C}_{6} \mathrm{H}_{12} \mathrm{O}$ & 100.2 & 793 & 257.8 & 1.264 & 453.89 & 534.21 & 643.29 & 765.02 \\
\hline 16 & Hexanal (D) & C66251 & $\mathrm{C}_{6} \mathrm{H}_{12} \mathrm{O}$ & 100.2 & 792.5 & 257.3 & 1.56 & 237.69 & 256.85 & 298.56 & 316.81 \\
\hline 17 & Benzaldehyde & C100527 & $\mathrm{C}_{7} \mathrm{H}_{6} \mathrm{O}$ & 106.1 & 975.6 & 507 & 1.145 & 232.42 & 302.87 & 356.59 & 400.98 \\
\hline 18 & n-Nonanal & C124196 & $\mathrm{C}_{9} \mathrm{H}_{18} \mathrm{O}$ & 142.2 & 1103 & 765.3 & 1.481 & 147.74 & 124.97 & 123.93 & 110 \\
\hline 19 & 3-Methylbutanal (M) & C590863 & $\mathrm{C}_{5} \mathrm{H}_{10} \mathrm{O}$ & 86.1 & 648.9 & 153.9 & 1.169 & 498.2 & 419.74 & 397.01 & 260.11 \\
\hline 20 & 3-Methylbutanal (D) & C590863 & $\mathrm{C}_{5} \mathrm{H}_{10} \mathrm{O}$ & 86.1 & 646.2 & 152.7 & 1.406 & 157.91 & 111.17 & 92.31 & 56.65 \\
\hline 21 & 2-Methylbutanal (M) & C96173 & $\mathrm{C}_{5} \mathrm{H}_{10} \mathrm{O}$ & 86.1 & 667.7 & 162.7 & 1.164 & 172.2 & 163.62 & 154.96 & 143.92 \\
\hline 22 & 2-Methylbutanal (D) & C96173 & $\mathrm{C}_{5} \mathrm{H}_{10} \mathrm{O}$ & 86.1 & 667.7 & 162.7 & 1.4 & 263.97 & 231.09 & 210.64 & 186.84 \\
\hline 23 & (E)-2-Pentenal (M) & C1576870 & $\mathrm{C}_{5} \mathrm{H}_{8} \mathrm{O}$ & 84.1 & 747.8 & 217.2 & 1.104 & 146.57 & 132.75 & 129.54 & 116.53 \\
\hline 24 & 2-Hexenal (M) & C505577 & $\mathrm{C}_{6} \mathrm{H}_{10} \mathrm{O}$ & 98.1 & 853.6 & 320.4 & 1.179 & 166.87 & 156.54 & 146.83 & 136.59 \\
\hline 25 & Methylpropanal (M) & C78842 & $\mathrm{C}_{4} \mathrm{H}_{8} \mathrm{O}$ & 72.1 & 568 & 121.3 & 1.113 & 317.71 & 289.15 & 254.57 & 229.72 \\
\hline 26 & Methylpropanal (D) & C78842 & $\mathrm{C}_{4} \mathrm{H}_{8} \mathrm{O}$ & 72.1 & 570.3 & 122.1 & 1.282 & 214.97 & 201.43 & 198.34 & 187.5 \\
\hline 27 & Ethyl acetate (M) & C141786 & $\mathrm{C}_{4} \mathrm{H}_{8} \mathrm{O}_{2}$ & 88.1 & 609.6 & 137.1 & 1.094 & 184.81 & 143.91 & 100.19 & 58.11 \\
\hline 28 & Ethyl acetate (D) & C141786 & $\mathrm{C}_{4} \mathrm{H}_{8} \mathrm{O}_{2}$ & 88.1 & 611.6 & 137.9 & 1.336 & 120.57 & 109.78 & 82.49 & 53.92 \\
\hline 29 & Heptanal (M) & C111717 & $\mathrm{C}_{7} \mathrm{H}_{14} \mathrm{O}$ & 114.2 & 902.5 & 382.7 & 1.347 & 55.08 & 51.23 & 46.75 & 39.04 \\
\hline 30 & (Z)-4-Heptenal & C6728310 & $\mathrm{C}_{7} \mathrm{H}_{12} \mathrm{O}$ & 112.2 & 900.6 & 380.1 & 1.146 & 130.31 & 159.75 & 189.86 & 223.49 \\
\hline 31 & Trimethylamine & C75503 & $\mathrm{C}_{3} \mathrm{H}_{9} \mathrm{~N}$ & 59.1 & 496.6 & 98.26 & 1.148 & 1543.4 & 1665.65 & 1862.3 & 1950.94 \\
\hline
\end{tabular}

Note: The retention times and ion migration times are listed together with the compound name, CAS number, molecular formula, molecular weight (MW), reserved index (RI1), retention time (RT2), drift time (DT3), and response peaks after different storage periods.

\subsection{Identification of Volatile Compounds in Large Yellow Croaker during Storage}

To gain further insight into the volatile compounds present in large yellow croaker after different storage periods, GC-IMS was employed to identify the compounds by their retention times in the GC column and their ion migration times during IMS [32]. The results are displayed in Figure 3, wherein a total of 31 peaks, including 8 ketones, 6 alcohols, 12 aldehydes, 2 esters, 2 alkanes, and 1 amine, can be observed. Some other additional signals were also observed. As can be seen from Figure 3, dimers (D) and trimers (T) can also form from monomeric species (M), such as in the cases of 2-heptanone, 3-hydroxy2-butanone, 3-pentanone, 3-methylbutanol, hexanal, 2-methylbutanal, methylpropanal, and ethyl acetate, which were observed as both monomers (M) and dimers (D), while 3-methylbutanol was also observed as a trimer (T). The analyzed large yellow croaker meat was, therefore, determined to contain the following flavor components: 8 ketones, namely 3-octanone, 2-heptanone (M), 2-heptanone (D), 3-hydroxy-2-butanone (M), 3-hydroxy2-butanone (D), 3-pentanone (M), 3-pentanone (D), 2-butanone; 6 alcohols, namely 1hexanol, 3-methylbutanol (D), 1-penten-3-ol, 1-propanethiol, 3-methylbutanol (T), and ethanol; 14 aldehydes, namely hexanal (M), hexanal (D), benzaldehyde, n-nonanal, 3methylbutanal (M), 3-methylbutanal (D), 2-methylbutanal (M), 2-methylbutanal (D), (E)-2pentenal (M), 2-hexenal (M), methylpropanal (M), methylpropanal (D), heptanal (M), and (Z)-4-heptenal; 2 esters, namely ethyl acetate (M) and ethyl acetate (D); and 1 amine, namely trimethylamine. Therefore, when passing through the drift region, multiple signals can be 
observed for a single compound due to the formation of adducts between the analyzed ions and neutral molecules.
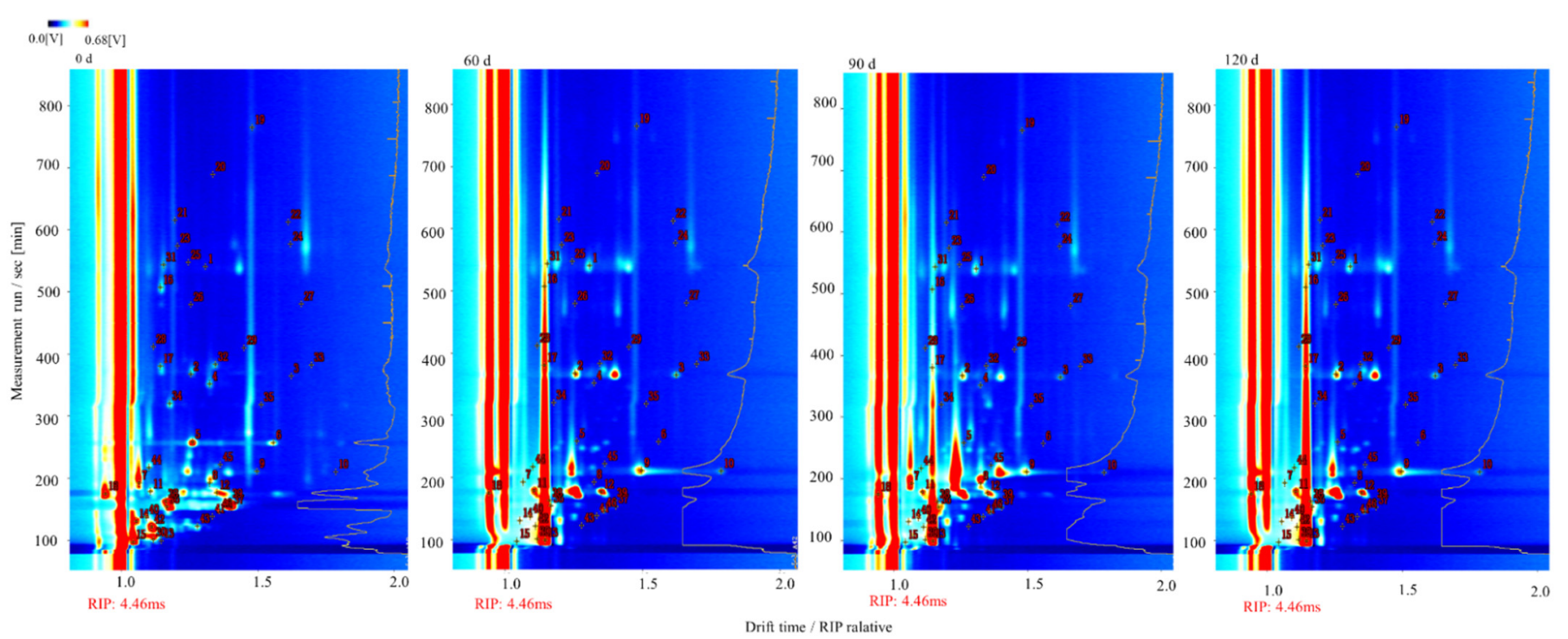

Figure 3. GC-IMS data for the large yellow croaker fish meat after different storage periods ( $x$-axis: the ion migration time, $y$-axis: the GC retention time).

Figure 4 shows a plot of the signal strengths measured by the different sensors of the electronic nose during evaluation of the fish meat samples. With a prolonged storage time, the signals from the $\mathrm{W} 3 \mathrm{C}, \mathrm{W} 6 \mathrm{~S}, \mathrm{~W} 2 \mathrm{~W}, \mathrm{~W} 3 \mathrm{~S}$, and $\mathrm{W} 1 \mathrm{C}$ sensors became stronger, indicating that the large yellow croaker meat accumulated aromatic compounds and hydrogen peroxide. In contrast, the signal related to the organic sulfide compound decreased between 0 and $90 \mathrm{~d}$, and then rebounded again at $120 \mathrm{~d}$. This resembles the observations reported by Meng in terms of the formation of heterocyclic aromatic compounds and the associated changes in flavor [33]. From the data measured by the W2W and W6S sensors, it is apparent that the fish flavor is largely determined by organic sulfides and hydrides, while amines play a smaller role [34].

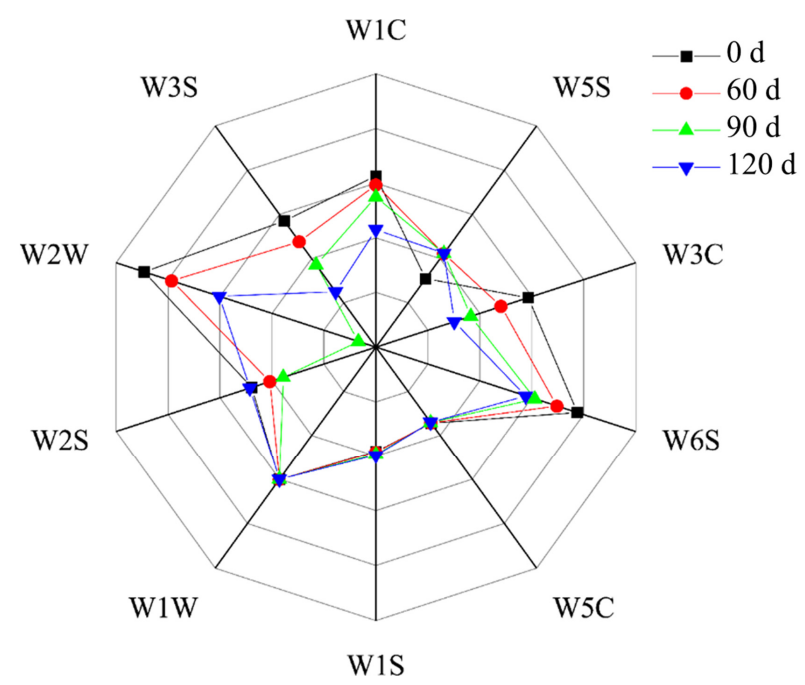

Figure 4. Effect of the storage period on the volatile flavor compounds present in fish meat, as measured using different sensors of an electronic nose. Note: W1C: aromatics; W5S: nitrogen oxides; W3C: ammonia and aromatic components; W6S: hydride; W5C: olefins and aromatic molecules; W1S: methane; W1W: sulfide; W2S: ethanol and some aromatics; W2W: organic sulfides: W3S: alkanes and aliphatics. 


\subsection{Topographic Map of the Volatile Components Present in Large Yellow Croaker at Different Storage Times}

To comprehensively explore the volatile compounds present in the fish meat at different storage times, a topographic map was obtained for the normalized GC-IMS data (Figure 5), wherein the red vertical line indicates the reaction ion peak (RIP), and each point on the right-hand side of the RIP represents a different volatile compound that is present in the sample. As can be seen from the figure, intense signals were observed between retention times of 100 and $300 \mathrm{~s}$ and drift times of 0.7 and $1.5 \mathrm{~s}$. In the normalized two-dimensional plots, red (blue) indicates an increase (decrease) in the volatile compound concentration compared to the reference $[35,36]$. It has also been suggested that the drift rate is related to the concentration of such compounds in the fish samples [37].

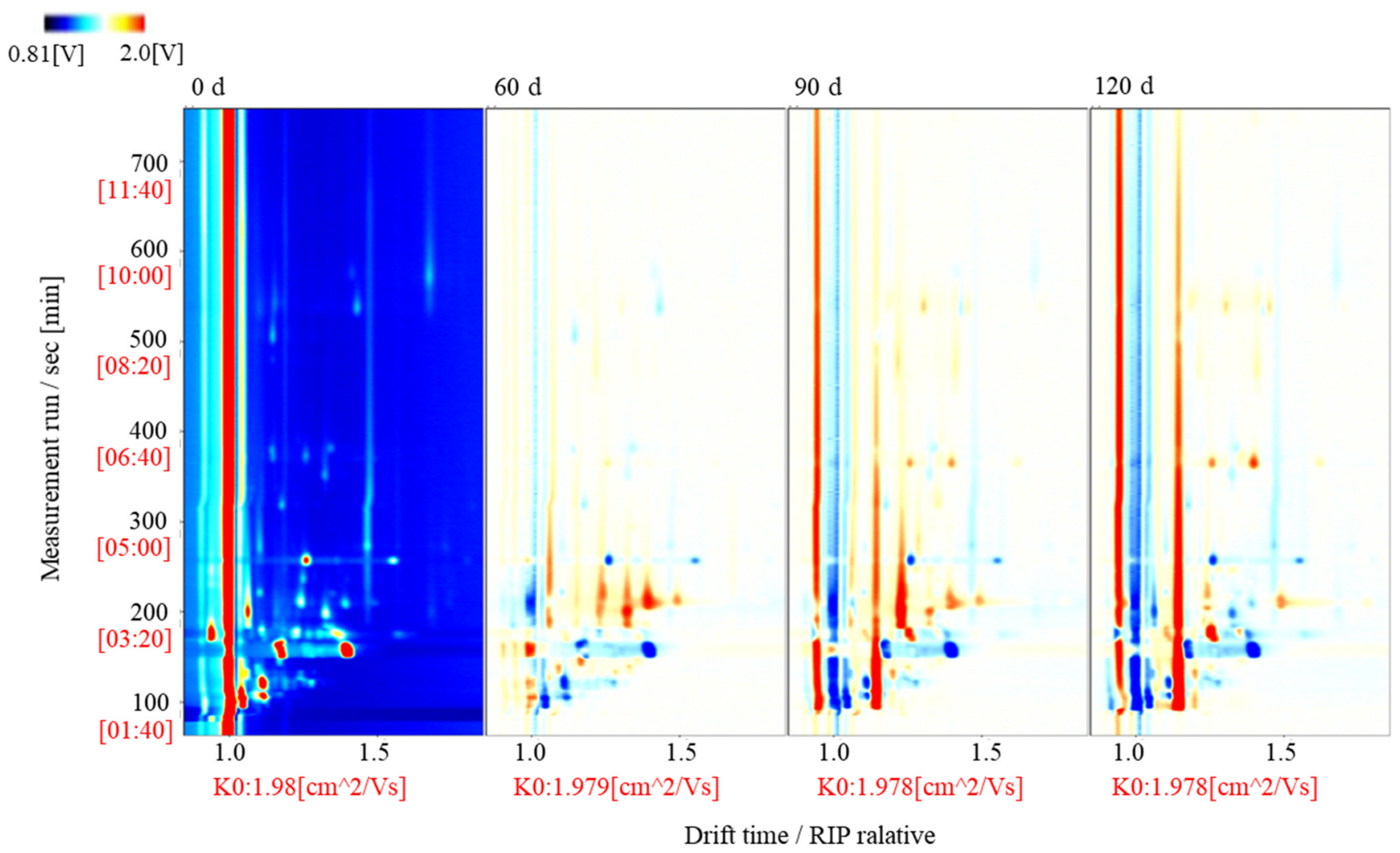

Figure 5. Two-dimensional topographic map of the normalized GC-IMS data for the fish samples subjected to different storage periods.

3.4. Variations in the Volatile Flavor Compounds Present in Large Yellow Croaker after Different Storage Periods

To further compare the volatile flavor compounds present in the fish samples after different storage periods, all peaks in the 2D GC-IMS map were analyzed to establish a fingerprint map (Figure 6). In this map, each row displays all signal peaks from the same sample, while each column shows the signal peaks for the same volatile compounds measured in triplicate for each storage time. More specifically, each heat map indicates the content of the given volatile compound [38]. Such fingerprints provide a panoramic view of all the volatile compounds present in the samples after different storage periods, and a number of unidentified substances are also displayed (Arabic numerals 1-8) [39-41]. 


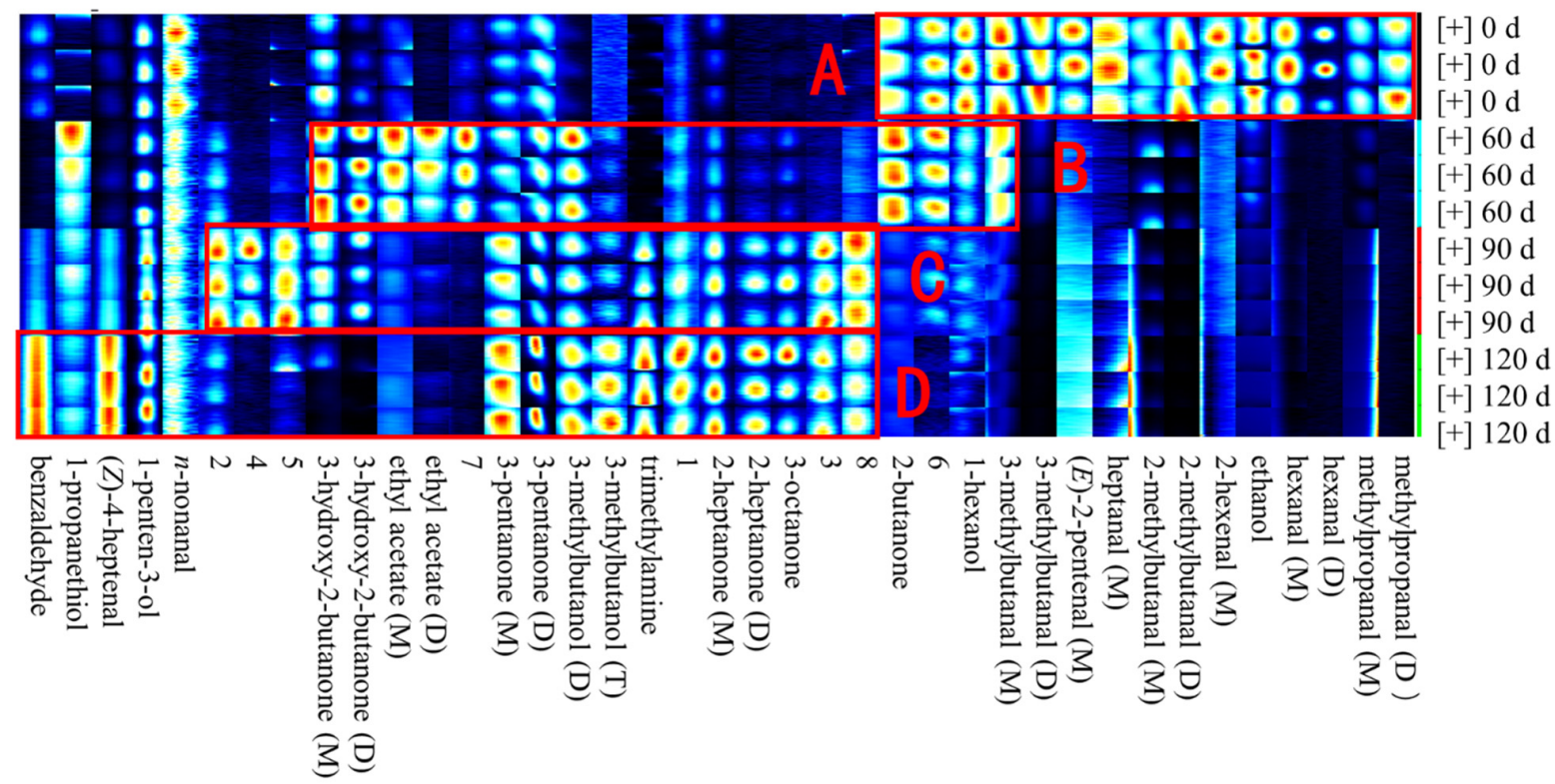

Figure 6. Fingerprint map of the volatile organic compounds present in large yellow croaker after different storage periods. Note: A-D represents that the storage periods of fish meat samples are $0 \mathrm{~d}, 60 \mathrm{~d}, 90 \mathrm{~d}$ and $120 \mathrm{~d}$, respectively.

Based on the data presented in Figures 4 and 6, it is apparent that the fish meat of large yellow croaker contains different volatile organic compound fingerprints after the various storage times. For example, compared with the samples stored for 60,90 , and $120 \mathrm{~d}$, a greater aldehyde content was present in the initial sample (see Table 1), which is consistent with the findings of Duan [42]. It should be noted here that aldehydes possess a low flavor threshold in addition to a characteristic fat aroma at low concentrations [43]. In the fresh fish meat (i.e., at day 0), the key volatile organic compounds present (area A, Figure 6) were methylpropanal (D), methylpropanal (M), hexanal (D), hexanal (M), ethanol, 2-hexenal (M), and 2-methylbutanal (D). Upon increasing the storage period to $60 \mathrm{~d}$, the flavor attributed to 1-hexanol was reduced and had essentially disappeared after $90 \mathrm{~d}$. This may be because oxidative deterioration of the meat proteins dissipated the 1-hexanol flavor [44]. Furthermore, after storage for $60 \mathrm{~d}$, the contributions from ethyl acetate (D), ethyl acetate (M), 3-hydroxy-2-butanone (D), and 3-hydroxy-2-butanone (M) to the fish flavor were significant, with 3-hydroxy-2-butanone (M) being the key component affecting the fish meat flavor during this period (see Figure 6). This compound is known to mainly originate from the oxidation of palmitic acid, stearic acid, and oleic acid [45]. Subsequently, it was found that beyond $60 \mathrm{~d}$ of storage, the main flavor components of the large yellow croaker meat were ethyl acetate (D) and ethyl acetate (M), which have a fat-like flavor. However, the oxidation of such compounds produces a pungent smell, similar to that of rotten eggs [46]. In addition, the contributions by the 3-methylbutyraldehyde (D) and 3-methylbutyraldehyde (M) components were more significant after 90 and $120 \mathrm{~d}$, with the highest content being reached after $120 \mathrm{~d}$. It should be noted here that when humans consume fish meat at this stage of oxidation, they will experience chest tightness, nausea, vomiting, fatigue, and weakness, as previously reported [47]. Although aldehydes are the most abundant compounds in pickled products, if their content is too high, a strong pungent smell is produced along with a greasy and oily/waxy odor, and the consumption of such compounds can be detrimental to human health. Our results, therefore, clearly indicate that after $120 \mathrm{~d}$ storage, the spoilage of fish meat takes place, leading to increased ketone and alcohol contents [48]. As described previously, short-chain aldehydes can interact with protein aggregates to produce a fatty flavor [49]. After a period of storage, putrefaction can take place, which can produce a rancid smell due to the production of such volatile aldehydes during the microbial degradation of free cysteine and methionine in the fish muscle [50]. Ketones also play a similar role in the flavor deterioration of large 
yellow croaker meat due to their increased production by lipid oxidation and microbial degradation [51].

\subsection{PCA of the Characteristic Flavor Compounds Present in Large Yellow Croaker}

Finally, delving deeper into the GC-IMS and GC-MS results, we performed PCA based on the fingerprint map of the volatile organic compounds (Figure 7). This method generates principal components that are linear combinations of the input variables, and it is effective for reducing the number of variables and removing abnormal data. According to the PCA results, the accumulative variance contribution rate of PC-1 (61\%) and PC-2 (26\%) was $87 \%$, thereby indicating that it was facile to distinguish between the large yellow croaker meat samples from different storage periods, as can be seen in the figure. As outlined in Table 1, some volatile organic compounds (e.g., 3-hydroxy-2-butanone (M), 3-hydroxy-2-butanone (D), 3-pentanone (D), ethanol, and trimethylamine) were more common prior to storage, while others (i.e., 3-octanone, 2-heptanone (M), 3-pentanone (M), and 3-methylbutanol (D)) were present primarily beyond $60 \mathrm{~d}$ of storage, and some compounds (i.e., 3-pentanone (D), benzaldehyde, (Z)-4-heptenal, and trimethylamine) dominated after $120 \mathrm{~d}$. These results are in agreement with the fingerprint map analysis presented in Figure 6. As shown in the PCA plot of the volatiles identified by GC-MS (Figure 7), PC-1 had a remarkable influence on the large yellow croaker meat samples over the various storage periods, and the day 0 samples differed significantly from those at $60 \mathrm{~d}(p<0.05)$. Indeed, this difference increased further when the storage period was prolonged to 90 and $120 \mathrm{~d}$. This gradual change in the flavor components during storage is similar to previously reported findings for salmon fillets [52]. Overall, our results indicate that the flavor characteristics of large yellow croaker meat were successfully established using GC-IMS for the various storage periods. In addition, the clustering of the triplicate data confirms the good reproducibility of this measurement method. Thus, we were able to obtain an improved understanding of lipid oxidation in the meat of large yellow croaker during frozen storage by quantitative analysis of the volatile flavor compounds.

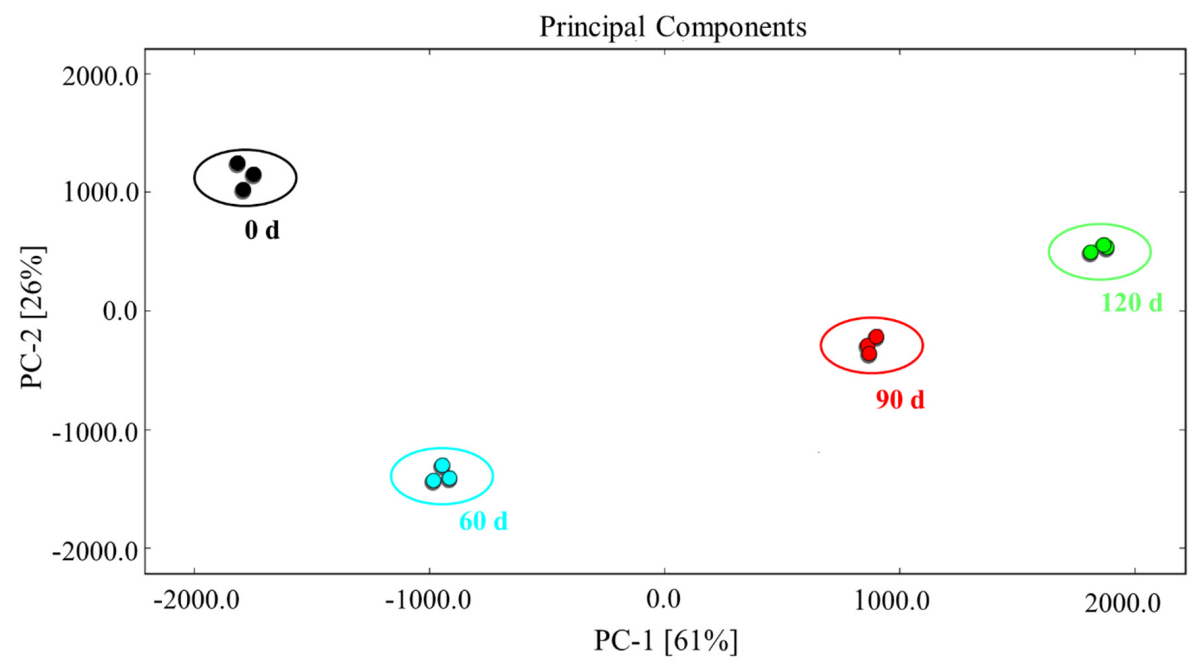

Figure 7. PCA analysis of the characteristic flavor compounds present in large yellow croaker meat after different storage periods.

\section{Conclusions}

To explore the changes in flavor of large yellow croaker fish meat during storage, the main physical and chemical characteristics of the fish meat, including the acid value, the peroxide value, the $p$-anisidine value, the conjugated diene value, and the identities of the various flavor substances, were investigated and analyzed by multivariable methods, including headspace gas chromatography-ion mobility spectrometry (GC-IMS) and principal component analysis (PCA). Significant changes were observed in the volatile organic compounds present in the meat samples during storage for periods up to $120 \mathrm{~d}$. A total of 
31 volatile compounds were identified by GC-IMS, including aldehydes, ketones, alcohols, esters, and alkanes. Aldehydes accounted for the largest number of these 31 identified species, followed by ketones and alcohols. The GC-IMS data were further used to construct fingerprint maps to highlight the characteristic molecular species present at each stage during storage, and the distinct fingerprint maps were corroborated by results from PCA for the samples at $0,60,90$, and $120 \mathrm{~d}$. The techniques employed herein could, therefore, be employed to improve quality control and inventory monitoring, as well as for analyzing the flavor components present in other foodstuffs during storage. In order to ensure the smooth progress of this research, our team is still working in relation to this project, I hope you can look forward to our future work report.

Supplementary Materials: The following are available online at https:/ /www.mdpi.com/article/10 $.3390 /$ foods10122917/s1, Table S1: Different sensors used to detect aromas by the electronic nose.

Author Contributions: T.Z:: investigation, methodology, formal analysis, data curation, and writingoriginal draft. S.B. and C.S.: validation and writing-review and editing. X.Y. and L.M.: conceptualization, project administration, supervision, and writing — review and editing. G.X., J.Y., and G.L.: supervision and validation. S.D.: validation and writing-review and editing. All authors have read and agreed to the published version of the manuscript.

Funding: The work was financed by the following agencies: the National Key Research and Development Program of China (Project No. 2018YFC1602101), the National Natural Science Fund of China (Project No. 32001622), the Zhejiang Province Key R\&D Program (Project No. 2019C02075), the Guangdong Basic and Applied Research Foundation (Project No. 2021A1515011060), the Fundamental and Applied Basic Research Fund for Young Scholars of Guangdong Province (Project No. 2019A1515110823), the Science and Technology Commissioner Project of Guangzhou (Project No. GZKTP201937), the Guangdong University Youth Innovation Talent Project (Project No. KA2001957), the Key Generic Technology System of the Agricultural Industry in Guangdong Province (Project No. 2019KJ139), the Guangdong Key Laboratory of Science and Technology of Lingnan Specialty Food (Project No. 2021B1212040013), and the Scientific Research Business of Colleges and Universities in Zhejiang Province (Grant No. 2021JZ010).

Institutional Review Board Statement: All fish and aquatic gave their informed consent for inclusion before they participated in the study. The study was conducted in accordance with the Declaration of Helsinki, and the protocol was approved by the Ethics Committee of the animal production license No. of Zhejiang animal ethics committee: SYXK (Zhejiang) 2021-0025, Meat quality certificate of Food Co., Ltd.: 30000490535 approved for use.

Informed Consent Statement: Informed consent was obtained from all subjects involved in the study.

Data Availability Statement: The data that support the findings of this study are available from the corresponding author upon reasonable request.

Acknowledgments: We thank the Key Laboratory of Seafood Health Risk Factors of Zhejiang Ocean University for providing the scientific research platform.

Conflicts of Interest: None of the authors had any conflict of interest in this work.

$\begin{array}{ll}\text { Abbreviations } \\ \text { AV } & \text { acid value } \\ \text { CDV } & \text { conjugated diene value } \\ \text { GC } & \text { gas chromatography } \\ \text { HS } & \text { headspace } \\ \text { IMS } & \text { ion mobility spectrometry } \\ \text { MS } & \text { mass spectrometry } \\ \text { p-AV } & p \text {-anisidine value } \\ \text { POV } & \text { peroxidation value } \\ \text { PCA } & \text { principal component analysis } \\ \text { RIP } & \text { reaction ion peak } \\ \text { SPME } & \text { solid-phase microextraction }\end{array}$




\section{References}

1. Xuan, M.; Jun, M.; Jing, X. Effects of multi-frequency ultrasound on the freezing rates, quality properties and structural characteristics of cultured large yellow croaker (Larimichthys crocea). Ultrason Sonochem. 2021, 76, 105657-105669. [CrossRef]

2. Wang, S.N.; Das, A.K.; Pang, J.; Liang, P. Artificial Intelligence Empowered Multispectral Vision Based System for Non-Contact Monitoring of Large Yellow Croaker (Larimichthys crocea) Fillets. Foods 2021, 10, 1161. [CrossRef]

3. Chen, Y.; Huang, W.; Shan, X.; Chen, J.; Weng, H.; Yang, T.; Wang, H. Growth characteristics of cage-cultured large yellow croaker Larimichthys crocea. Aquacult. Rep. 2020, 16, 100242-100248. [CrossRef]

4. Du, Y.N.; Xue, S.; Han, J.R.; Yan, J.N.; Shang, W.H.; Hong, J.N.; Wu, H.T. Simultaneous extraction by acidic and saline solutions and characteristics of the lipids and proteins from large yellow croaker (Pseudosciaena crocea) roes. Food Chem. 2020, 310, 125928-125938. [CrossRef] [PubMed]

5. Grazina, L.; Rodrigues, P.J.; Nunes, M.A.; Mafra, I.; Arlorio, M.; Oliveira, M.; Beatriz, P.P.; Amaral, J.S. Machine Learning Approaches Applied to GC-FID Fatty Acid Profiles to Discriminate Wild from Farmed Salmon. Foods 2020, 9, 1622. [CrossRef] [PubMed]

6. $\quad$ Fei, H.; Jiawen, D.; Jiwen, Z.; Hehe, L.; Jinyuan, S.; Mingquan, H.; Baoguo, S. Different distillation stages Baijiu classification by temperature-programmed headspace-gas chromatography-ion mobility spectrometry and gas chromatography-olfactometrymass spectrometry combined with chemometric strategies. Food Chem. 2021, 365, 130430-130439. [CrossRef]

7. Fang, W.; Yaqin, G.; Hongbo, W.; Bin, X.; Xiaona, H.; Xiaoling, Y.; Weihong, L. Analysis of volatile compounds and flavor fingerprint in Jingyuan lamb of different ages using gas chromatography-ion mobility spectrometry (GC-IMS). Meat Sci. 2021, 175, 108449-108458. [CrossRef]

8. Mingjie, C.; Tong, C.; Xingpu, Q.; Daoli, L.; Bin, C. Analyzing changes of volatile components in dried pork slice by gas chromatography-ion mobility spectroscopy. CyTA-J. Food. 2020, 18, 328-335. [CrossRef]

9. Yi, C.; Pao, L.; Luyan, L.; Yeyou, Q.; Liwen, J.; Yang, L. Characteristic fingerprints and volatile flavor compound variations in Liuyang Douchi during fermentation via HS-GC-IMS and HS-SPME-GC-MS. Food Chem. 2021, 361, 13005-13015. [CrossRef]

10. del Mar Contreras, M.; Jurado, N.; Arce, L.; Arroyo, N. A robustness study of calibration models for olive oil classification: Targeted and non-targeted fingerprint approaches based on GC-IMS. Food Chem. 2019, 288, 315-324. [CrossRef]

11. Juan, Y.; Siliang, W.; Ruijie, M.; Li, L.; Wenhong, Z.; Weidong, B. Formation of amino acid-derived volatile compounds in dry-cured mackerel (Scomberomorus niphonius): Metabolic pathways involving microorganisms, precursors, and intermediates. Food Chem. 2021, 364, 130163-130173. [CrossRef]

12. Siliang, W.; Juan, Y.; Hao, D.; Qiaoyu, L.; Xiangluan, L.; Xiaofang, Z.; Weidong, B. Key aroma compounds of Chinese dry-cured Spanish mackerel (Scomberomorus niphonius) and their potential metabolic mechanisms. Food Chem. 2021, 342, 128381-128391. [CrossRef]

13. Siyang, D.; Yunhe, L.; Feng, H.; Jiqian, L.; Dong, H.; Chunhui, Z.; Christophe, B. Evaluation of volatile flavor compounds in bacon made by different pig breeds during storage time. Food Chem. 2021, 357, 29765-129775. [CrossRef]

14. Wang, S.; Chen, H.; Sun, B. Recent progress in food flavor analysis using gas chromatography-ion mobility spectrometry (GC-IMS). Food Chem. 2020, 315, 126158-126168. [CrossRef]

15. Aheto, J.H.; Huang, X.; Tian, X.; Lv, R.; Dai, C.; Bonah, E.; Chang, X. Evaluation of lipid oxidation and volatile compounds of traditional dry-cured pork belly: The hyperspectral imaging and multi-gas-sensory approaches. J. Food Process Eng. 2020, 43, 13092-13101. [CrossRef]

16. Kunyaboon, S.; Thumanu, K.; Park, J.W.; Khongla, C.; Yongsawatdigul, J. Evaluation of Lipid Oxidation, Volatile Compounds and Vibrational Spectroscopy of Silver Carp (Hypophthalmichthys molitrix) during Ice Storage as Related to the Quality of Its Washed Mince. Foods 2021, 10, 495. [CrossRef] [PubMed]

17. Morsy, M.K.; Zór, K.; Kostesha, N.; Alstrøm, T.S.; Heiskanen, A.; ElTanahi, H.; Sharoba, A.; Papkovsky, D.; Larsen, J.; Khalaf, H.; et al. Development and validation of a colorimetric sensor array for fish spoilage monitoring. Food Cont. 2016, 60, 346-352. [CrossRef]

18. Khan, I.T.; Nadeem, M.; Imran, M.; Khalique, A. Impact of post fermentation cooling patterns on fatty acid profile, lipid oxidation and antioxidant features of cow and buffalo milk set yoghurt. Lipids Health Dis. 2020, 19, 62-74. [CrossRef] [PubMed]

19. Ma, L.; Liu, G.; Cheng, W.; Liu, X.; Brennan, C.; Brennan, M.A.; Liu, H.; Wang, Q. The effect of heating on the formation of 4-hydroxy-2-hexenal and 4-hydroxy-2-nonenal in unsaturated vegetable oils: Evaluation of oxidation indicators. Food Chem. 2020, 321, 126603-126613. [CrossRef]

20. Emre, Y. Determination of fish quality parameters with low costs electronic nose. Food Biosci. 2021, 41, 100948. [CrossRef]

21. Tu, C.H.; Qi, X.E.; Shui, S.S.; Lin, H.M.; Benjakul, S.; Zhang, B. Investigation of the changes in lipid profiles induced by hydroxyl radicals in whiteleg shrimp (Litopenaeus vannamei) muscle using LC/MS-based lipidomics analysis. Food Chem. 2021, 369, 130925-130934. [CrossRef]

22. Elavarasan, K.; Shamasundar, B.A. Antioxidant properties of papain mediated protein hydrolysates from fresh water carps (Catla catla, Labeo rohita and Cirrhinus mrigala) and its application on inhibition of lipid oxidation in oil sardine mince during ice storage. J. Food Sci. Technol. 2021, 1-10. [CrossRef]

23. Thimmappa, M.H.; Reddy, A.M.; Prabhu, R.M.; Elavarasan, K. Quality Changes in Deep-Sea Shrimp (Aristeus alcocki) During Ice Storage: Biochemical and Organoleptic Changes. Aquacult. Rep. 2019, 8, 497-504. [CrossRef] 
24. Lin, H.X.; Yang, Q.H.; Wang, A.J.; Wang, J.X.; Tan, B.P.; Ray, G.W.; Dong, X.H.; Chi, S.Y.; Liu, H.Y.; Zhang, S. Effects of fish meal under different storage conditions on growth, serum biochemical indices and antioxidant capacity for juvenile grouper Epinephelus coioides. Aquacult. Nutr. 2021, 27, 723-733. [CrossRef]

25. Phung, A.S.; Bannenberg, G.; Vigor, C.; Reversat, G.; Oger, C.; Roumain, M.; Galano, J.M.; Durand, T.; Muccioli, G.G.; Ismail, A.; et al. Chemical Compositional Changes in Over-Oxidized Fish Oils. Foods 2020, 9, 1501. [CrossRef] [PubMed]

26. Malik, I.A.; Elgasim, E.A.; Adiamo, O.Q.; Ali, A.A.; Mohamed, A.I.A. Effect of frozen storage on the biochemical composition of five commercial freshwater fish species from River Nile, Sudan. Food Sci. Nutr. 2021, 9, 3758-3767. [CrossRef] [PubMed]

27. Crexi, V.T.; Monte, M.L.; de Souza Soares, L.A.; Pinto, L.A.A. Production and refinement of oil from carp (Cyprinus carpio) viscera. Food Chem. 2009, 119, 945-950. [CrossRef]

28. Dian, G.Z.; Tao, Z.; Christer, H.; Han, M.Y.; Xiao, J.X.; Zhi, L. Oxidized fish oils increased lipid deposition via oxidative stressmediated mitochondrial dysfunction and the CREB1-Bcl2-Beclin1 pathway in the liver tissues and hepatocytes of yellow catfish. Food Chem. 2021, 360, 129814-129822. [CrossRef]

29. Sullivan, J.C.; Budge, S.M. Fish oil sensory properties can be predicted using key oxidative volatiles. Eur. J. Lipid Sci. Technol. 2012, 114, 496-503. [CrossRef]

30. Ye, L.Y.; Harris, E.; Budge, S.M.; Sullivan, R.J. Flavors' Decreasing Contribution to p-Anisidine Value over Shelf Life May Invalidate the Current Recommended Protocol for Flavored Fish Oils. J. Am. Oil Chem. Soc. 2020, 97, 1335-1341. [CrossRef]

31. Iberahim, N.I.; Tan, B.C. Hexane-isopropanol Extraction and Quality Assessment of Omega-3 Fish Oil From Atlantic Salmon (Salmo salar). IOP Conf. Ser. Mater. Sci. Eng. 2020, 932, 012038-012048. [CrossRef]

32. Jia, S.; Li, Y.; Zhuang, S.; Sun, X.; Zhang, L.; Shi, J.; Hong, H.; Luo, Y. Biochemical changes induced by dominant bacteria in chill-stored silver carp (Hypophthalmichthys molitrix) and GC-IMS identification of volatile organic compounds. Food Microbiol. 2019, 84, 103284-103293. [CrossRef] [PubMed]

33. Meng, L.; Songyi, L.; Ruichun, W.; Duo, G.; Zhi, J.B.; Dong, C.; Yue, T.; Na, S.; Simin, Z. Inhibitory effect and mechanism of various fruit extracts on the formation of heterocyclic aromatic amines and flavor changes in roast large yellow croaker (Pseudosciaena crocea). Food Cont. 2022, 131, 108410. [CrossRef]

34. Sofia, S.A.; Miguel, R.A.L.; Relvas, J.B.; Estevez, P.M. Fatty acid role on obesity induced hypothalamus inflammation: From problem to solution-A review. Trends Food Sci. Technol. 2021, 112, 592-607. [CrossRef]

35. Zhenkun, C.; Han, Y.; Tatiana, M.; Haizhen, M.; Hongbo, L.; Hao, Z. Changes in the volatile components of squid (Illex argentinus) for different cooking methods via headspace-gas chromatography-ion mobility spectrometry. Food Sci. Nutr. 2020, 8, 5748-5762. [CrossRef]

36. Zelin, D.; Shuanglin, D.; Yunwei, D.; Qinfeng, G. Geographical origin identification of two salmonid species via flavor compound analysis using headspace-gas chromatography-ion mobility spectrometry combined with electronic nose and tongue. Food Res. Int. 2021, 145, 110385-110395. [CrossRef]

37. Zhang, B.; Yan, H.B.; Su, L.J.; Chen, X.N. Kappa-carrageenan oligosaccharides retard the progression of protein and lipid oxidation in mackerel (Scomber japonicus) fillets during frozen storage. RSC Adv. 2020, 10, 20827-20836. [CrossRef]

38. Wensheng, Y.; Yingxuan, C.; Dengyong, L.; Zhinan, Z.; Zhenghao, Z.; Shuangyu, M.; Mingcheng, Z.; Hao, Z. Comparative analysis of characteristic volatile compounds in Chinese traditional smoked chicken (specialty poultry products) from different regions by headspace-gas chromatography-ion mobility spectrometry. Poult. Sci. 2020, 99, 7192-7201. [CrossRef]

39. Hua, Q.; Gao, P.; Xu, Y.; Xia, W.; Sun, Y.; Jiang, Q. Effect of commercial starter cultures on the quality characteristics of fermented fish-chili paste. LWT-Food Sci. Technol. 2020, 122, 109016-109026. [CrossRef]

40. Chen, Y.P.; Cai, D.; Li, W.; Blank, I.; Liu, Y. Application of gas chromatography-ion mobility spectrometry (GC-IMS) and ultrafast gas chromatography electronic-nose (uf-GC E-nose) to distinguish four Chinese freshwater fishes at both raw and cooked status J. Food Biochem. 2021, 6, e13840-e13849. [CrossRef]

41. Yu, L.; Wang, Y.; Wen, H.; Jiang, M.; Wu, F.; Tian, J. Synthesis and evaluation of acetylferulic paeonol ester and ferulic paeonol ester as potential antioxidants to inhibit fish oil oxidation. Food Chem. 2021, 365, 130384-130394. [CrossRef]

42. Duan, Z.; Dong, S.; Sun, Y.; Dong, Y.; Gao, Q. Response of Atlantic salmon (Salmo salar) flavor to environmental salinity while culturing between freshwater and seawater. Aquaculture 2021, 530, 735953-735962. [CrossRef]

43. Bartual, A.; Hernanz-Torrijos, M.; Sala, I.; Ortega, M.J.; González-García, C.; Bolado-Penagos, M.; López-Urrutia, A.; RomeroMartínez, L.; Lubián, L.M.; Bruno, M.; et al. Types and Distribution of Bioactive Polyunsaturated Aldehydes in a Gradient from Mesotrophic to Oligotrophic Waters in the Alborán Sea (Western Mediterranean). Mar. Drugs. 2020, 18, 159. [CrossRef] [PubMed]

44. Chen, X.; Luo, J.; Lou, A.; Wang, Y.; Yang, D.; Shen, Q.W. Duck breast muscle proteins, free fatty acids and volatile compounds as affected by curing methods. Food Chem. 2021, 338, 128138-128148. [CrossRef]

45. Huang, L.; Zeng, X.; Sun, Z.; Wu, A.; He, J.; Dang, Y.; Pan, D. Production of a safe cured meat with low residual nitrite using nitrite substitutes. Meat Sci. 2020, 1629, 108027-108036. [CrossRef]

46. Qi, Z.; Yicheng, D.; Saiqi, G.; Shichen, Z.; Xuxia, Z.; Yuting, D. Identification of changes in volatile compounds in dry-cured fish during storage using HS-GC-IMS. Food Res. Int. 2020, 137, 109339-109349. [CrossRef]

47. Tan, M.T.; Xie, J. Exploring the Effect of Dehydration on Water Migratng Property and Protein Changes of Large Yellow Croaker (Pseudosciaena crocea) during Frozen Storage. Foods 2021, 10, 784. [CrossRef] 
48. Nguyen, N.T.P.; Nguyen, L.V.H.; Tran, N.M.P.; Nguyen, D.T.; Nguyen, T.N.T.; Tran, H.A.; Dang, N.N.T.; Vo, T.V.; Nguyen, T.H. The effect of oxidation degree and volume ratio of components on properties and applications of in situ cross-linking hydrogels based on chitosan and hyaluronic acid. Mater. Sci. Eng. C Mater. Biol. Appl. 2019, 103, 109670-109679. [CrossRef]

49. Peipei, D.; Xianchao, F.; Xingguang, C.; Qinhao, G.; Junlan, W.; Shan, Q.; Xinglian, X.; Guanghong, Z.; Niamat, U.; Beiwei, Z.; et al. Binding of aldehyde flavour compounds to beef myofibrillar proteins and the effect of nonenzymatic glycation with glucose and glucosamine. LWT-Food Sci. Technol. 2021, 144, 111198. [CrossRef]

50. Yokouchi, C.; Nishimura, Y.; Goto, H.; Sato, M.; Hidoh, Y.; Takeuchi, K.; Ishii, Y. Reduction of fatty liver in rats by nicotinamide via the regeneration of the methionine cycle and the inhibition of aldehyde oxidase: Original Article. J. Toxicol. Sci. 2021, 46, 31-42. [CrossRef]

51. Chen, Q.; Wang, X.; Cong, P.; Liu, Y.; Wang, Y.; Xu, J.; Xue, C. Mechanism of Phospholipid Hydrolysis for Oyster Crassostrea plicatula Phospholipids During Storage Using Shotgun Lipidomics. Lipids 2017, 52, 1045-1058. [CrossRef] [PubMed]

52. Jia, Z.; Shi, C.; Wang, Y.; Yang, X.; Zhang, J.; Ji, Z. Nondestructive determination of salmon fillet freshness during storage at different temperatures by electronic nose system combined with radial basis function neural networks. Int. J. Food Sci. Technol. 2020, 55, 2080-2091. [CrossRef] 